\title{
Cuestiones de ceremonial y protocolo en las cortes de Cádiz¹.
}

\section{Ceremonial and protocol issues at "Cortes de Cádiz".}

\author{
Dolores del Mar Sánchez-González² \\ Universidad Nacional de Educación a Distancia \\ mdmsanchez@der.uned.es
}

Recepción: 02/06/2018 Revisión: 03/06/2018 Aceptación: 17/06/2018 Publicación: 30/06/2018

\section{Resumen}

Este trabajo demuestra cual es el momento exacto en que se produce la separación entre el protocolo y ceremonial de corte y el protocolo y ceremonial de Estado en España: la formación de las Cortes de Cádiz en 1810. Estas Cortes surgen en medio de un proceso de invasión del territorio, vacío de poderes por la ausencia del rey por lo que necesitan de un instrumento que les sirva de propaganda y legitimación ante sus conciudadanos por ello el primer decreto fue la creación de las cortes y el segundo la atribución de unos tratamientos y garantizar el juramento y la lealtad política de todas las instituciones públicas del nuevo Estado de corte liberal que querían diseñar.

Palabras claves: Cortes de Cádiz, protocolo, ceremonial, primera norma de protocolo oficial, España, siglo XIX

\footnotetext{
${ }^{1}$ Este trabajo fue publicado gracias al GRUPO DE INVESTIGACIÓN DE HISTORIA DEL PENSAMIENTO JURÍDICOPOLÍTICO (GIHPJ-P) en el año 2012 las Actas del XIII CIP celebrado en San Fernando Cádiz del 7 al 9 de noviembre. Se vuelve a publicar a petición de muchos lectores que tienen dificultades para llegar al mismo y para facilitar su difusión en el resto de los países.

${ }^{2}$ Catedrático de Historia del Derecho y de las Instituciones de la Facultad de Derecho de la Universidad Nacional de Educación a Distancia (UNED), Académica correspondiente de la Real de Jurisprudencia y Legislación (España), directora del Máster Universitario (Oficial) en Protocolo y del Programa Modular en Comunicación, Protocolo y RRPP de la UNED, IP GIHPJ-P, doctoranda (segundo doctorado) en el Doctorado Internacional de Comunicación de la Universidad de Málaga (Spain). Full Professor of History of Law and Institutions of the Faculty of Law of the National University of Distance Education (UNED), corresponding Academician of the Royal Jurisprudence and Legislation (Spain), Director of the University Master (Official) in Protocol and of the Modular Program in Communication, Protocol and RRPP of the UNED, IP GIHPJ-P, PhD (second doctorate) in the International Doctorate of Communication of the University of Malaga (Spain)
} 


\begin{abstract}
This work shows what is the exact moment in which the separation between the protocol and ceremonial of court and the protocol and ceremonial of State in Spain takes place: the formation of the Cortes de Cádiz in 1810. These Cortes arise in the middle of a process of invasion of the territory, lack of powers for the absence of the king so they need an instrument that serves as propaganda and legitimacy to their fellow citizens so the first decree was the creation of the courts and the second the attribution of treatments and ensure the oath and the political loyalty of all the public institutions of the new liberal State that wanted to design.
\end{abstract}

Keywords: Cortes de Cádiz, protocol, ceremonial, first standard of official protocol, history of Spain, XIX century

\title{
Sumario
}

1. Introducción: El elemento normativo

2. Los tratamientos como manifestación de la ostentación del poder político y representación simbólica de la soberanía

3. Los juramentos como ritual alegórico solemne

4. Semiótica y cortes de Cádiz: las ceremonias como escenificación del poder establecido

5. Los escenarios: el elemento espacial material

6. Los públicos como elemento personal: comportamiento y dress code

7. Conclusiones

8. Bibliografía

9. Web grafía

\section{INTRODUCCIÓN: EL ELEMENTO NORMATIVO}

Las Cortes de Cádiz no sólo suponen el inicio del constitucionalismo en España, sino que también conformarán uno de los primeros pasos para la creación del que luego sería el Protocolo de Estado, diferenciado del Protocolo de Corte, centrado hasta entonces exclusivamente en la entonces llamada Etiqueta ${ }^{3}$. Son, además, un punto de inflexión

\footnotetext{
${ }^{3}$ Parto de la consideración de que el término "protocolo", es un vocablo de acuñación muy reciente -principios del siglo XX- frente al término genérico de "ceremonial", referido a las formalidades específicas de un acto, o al específica y más antiguo de "etiqueta", con el que se designaba la forma de comportarse el personal de la Casa Real en presencia de los monarcas durante la Edad Moderna, y que fue conformando el ceremonial de corte en España. Por tanto, el término protocolo era desconocido en esta época en la que nos encontramos, por lo que nosotros vamos a hacer aquí una reconstrucción dogmática basada en una sistematización terminológica actual. Previamente tengo que aclarar que yo creo que la palabra protocolo tiene dos significados. Strictu sensu el protocolo se limita a regular las ceremonias oficiales del Estado y la participación de las autoridades en las ceremonias, es decir, el protocolo en sentido estricto se reconduce al protocolo oficial o institucional, tal y como sostiene $\mathrm{M}$ a Teresa Otero. Pero hoy no se utiliza sólo con este carácter el vocablo, sino que amplio sensu
} 
importante entre el protocolo y el ceremonial de cortes propio del Antiguo Régimen y el ceremonial parlamentario tal y como va configurarse durante todo el siglo XIX hasta llegar a la actualidad. Pese a su supresión y a que el regreso del absolutismo recuperó el carácter estamental de las del Antiguo Régimen, arraigarán algunos de los nuevos principios ceremoniales de estas Cortes en el periodo isabelino. El establecimiento de la soberanía nacional y la separación de poderes no podía permanecer ajena al ceremonial y a cuestiones tan importantes para el protocolo como el tratamiento que tenían las propias instituciones del Estado ${ }^{4}$. Ello sin olvidar el simple hecho de la proclamación de la soberanía nacional condiciona extemporáneamente toda la proxemia de las sucesivas reuniones y abre al camino del ceremonial parlamentario.

Bajo el nombre de Ceremonias de Estado y de Palacio durante el siglo XIX inclusive se entendían incluidas estas ceremonias: recepción en los días de corte, recepción en el salón del trono, apertura de cortes, recepciones especiales de los cuerpos colegisladores, presentación de embajadores y ministros plenipotenciarios y residentes para entregar sus credenciales, jura de la constitución al acceder el rey al trono o al cumplir la mayoría de edad, jura del príncipe o princesa de Asturias, jura de ministros del despacho, matrimonio del rey/reina, nacimiento y bautizo de príncipes e infantes. Consideración distinta tenían las entradas a la corte, las audiencias, los convites y las ceremonias religiosas que no se consideraban ceremonias de Estado, aunque participaran de la ordenación general de Etiquetas.

Dentro de las ceremonias del Estado empiezan así a tener forma propia los actos realizados en el entorno parlamentario, aunque se solían limitar a las ceremonias de apertura, jura de Constitución a la llegada al trono del monarca o a su mayoría de edad y las juras del príncipe o princesa de Asturias. Los orígenes de la nueva forma de entender este ceremonial parten de las propias Cortes de Cádiz $^{5}$, si bien será desde la Constitución de 1837 cuando se inicie una regularidad en el ceremonial parlamentario ${ }^{6}$.

sería "el conjunto de normas, usos sociales y costumbres que determinan cual es el orden de celebración de un determinado acto o evento, bien público o privado" (Sánchez González, 2011: 23). El protocolo una guía procedimental, una guía de actuación genérica aplicable a unas situaciones concretas, espacial y temporalmente limitadas, en la que una organización establece una comunicación no verbal con sus públicos. Y esa situación concreta es la que adjetiva el protocolo, pudiendo hablarse de protocolo social, protocolo en la empresa, protocolo en el deporte, etc.

${ }^{4}$ Incluso después, la necesidad de adecuar todas las instituciones a lo preceptuado en la nueva Constitución, trascenderá de las propias barreras parlamentarias y llega a instalarse en la propia Casa Real a cuyo personal se le va a exigir un cambio. Así una Orden de 18 de junio de 1813, mandaba "substituir nombres españoles á los extranjeros de algunos empleos de palacio; y sobre uniformar su etiqueta a los términos y espíritu de la Constitución" (Colección de Decretos, tomo IV).

${ }^{5}$ Si bien es cierto que durante los siglos XVI y XVII, existieron Cortes en todos los reinos de España, surgidas de las de los distintos territorios de la Edad Media, estas Cortes tienen naturaleza estamental, y los problemas ceremoniales más importantes entre todas ellas fueron las precedencias entre las distintas ciudades. Coincidiendo con el inicio en toda Europa un declive muy intenso en las asambleas representativas, España no podía permanecer ajena al fenómeno. Tan sólo en Inglaterra, que partía de la premisa de la división de la 
Aunque las Cortes de Cádiz aúnan tradición y modernidad, suponen una ruptura total en el equilibro de fuerzas políticas conocido hasta ese momento, y un cambio radical en la concepción del poder en España, que ineludiblemente se reflejó en el protocolo de la época, en cuanto que el mismo no es más que una representación y escenificación del poder, o, como dice Otero Alvarado, es "una ordenación espacio-temporal de los ámbitos de poder establecido" (2009: 14). Y en el ceremonial de las Cortes de Cádiz, ya que el ceremonial es expresión de las relaciones públicas y "a través del ceremonial se proyecta la identidad y se percibe la imagen de la organización, acciones dirigidas a poner de relieve la posición de superioridad o al menos de protagonismo de quienes organizan el evento" (Otero Alvarado, 2005: 142). Y eso es lo que se pretendió desde el primer momento en las Cortes de Cádiz.

En el proceso de formación del ceremonial parlamentario de las Cortes de Cádiz podemos detectar cuatro fases diferenciadas en la conformación del elemento normativo o reglas de ordenación espacial:

- Desde la creación de la Junta Central y Suprema Gubernativa de España e Indias el 25 de septiembre de 1808 hasta su desaparición el 30 de enero de 1810. La Junta Central reunirá en su institución todos los poderes del Estado a la usanza del Monarca del Antiguo Régimen, lo que se manifiesta a efectos protocolarios por el tratamiento y la sede de la misma, como veremos. En esta fase se crea una Junta de Ceremonial el 25 de noviembre de 1809, dentro de la Junta Central, para encargarse específicamente de estas las cuestiones ceremoniales de las futuras Cortes ${ }^{7}$.

soberanía nacional entre el Rey y el Parlamento, la representatividad tendrá un componente de fortaleza, si bien no lejos de tensiones en algunos reinados. Pero siempre el carácter simbólico, y la legitimidad moral y la propaganda que tales organismos producían en la Monarquía, evitó su desaparición. El siglo XVIII supone el advenimiento de la monarquía absoluta. Este hecho junto con los Decretos de Nueva Planta tras la guerra de sucesión, condiciona en España la supresión de las Cortes de los distintos territorios y su unificación en unas Cortes nacionales, que nunca fueron Cortes mixtas sino Cortes castellanas a las que se permitía asistir a procuradores de otros territorios, y cuyo único motivo de convocatoria era la jura del heredero y en algún caso aislado la modificación del orden de sucesión. Los problemas de precedencia entre las Cortes se producen ahora entre las ciudades de la Corona de Aragón y las de Castilla. Incluso ya en el siglo XIX, podemos considerar como cortes tradicionales del Antiguo Régimen las realizadas en 1833 con motivo de la jura de la Princesa Isabel, convocadas por Fernando VII según el procedimiento tradicional.

${ }^{6}$ Tema sobre el que el doctor Manuel Casado Trigo, ha publicado Historia del protocolo en las Cortes Generales Españolas, Sanz y Torres, Madrid, 2016.

${ }^{7}$ Pronto se impuso la idea de convocar Cortes en la Junta Central, aunque de igual manera surge la necesidad de evaluar si se realizarán unas Cortes estamentales, a la antigua usanza, o constituyentes, rescatando la soberanía de la nación. A principios de 1809 la mayoría de los miembros de la Junta son proclives a la convocatoria de Cortes, aunque sin definirse cómo y bajo qué fundamentación. Por ello el Real Decreto de 22 de mayo de 1809 ordena por fin la convocatoria de Cortes, y la Junta Central manda que se convoque una Comisión de Cortes, que pronto se estructura en siete Juntas que trabajan en diferentes áreas temáticas, entre las que se encuentra la Junta de Ceremonial de Cortes, creada el 25 de noviembre de 1809 y también llamada Junta de Ceremonial de Congregación ${ }^{7}$. Esta junta desempeñó un papel esencial en las futuras Cortes, con la finalidad de "arreglar los puntos relativos a la forma en que deberán congregarse las Cortes, ceremonial que se debe observar en ellas, y todo lo demás perteneciente a la dignidad" (Escudero, 2011: XXVIII). Esta Junta fue la única que no contó con instrucciones específicas de Jovellanos para su actuación, al haberse encargado a Antonio Capmany de recoger todas las noticias históricas relativas a organización y ceremonias de Cortes de 
- Desde la creación del Consejo de Regencia de España e Indias (Suprema Regencia), el 31 de enero de 1810, hasta el 24 de noviembre de 1810 en que se publica el primer Reglamento para el gobierno interior de las Cortes (1810) que se imprimió y se repartió a los diputados para su observancia ${ }^{8}$. El 24 de septiembre de 1810 se habían reunido en la Isla de León, Cortes generales y extraordinarias y dos meses después se aprobaba este reglamento procedimental, que contiene importantes normas.

- Desde el Reglamento de 1810 hasta el traslado de las Cortes de Madrid (15/01/1814). El 04/09/1813 se aprobó el Reglamento para el gobierno interior de las Cortes (Decreto CCXCIII), de acuerdo con lo previsto en los artículos 122, 127 y 210 de la Constitución de 1812, que supone un ceremonial parlamentario más detallado.

- Con motivo del traslado de las Cortes a Madrid (Teatro de los Caños del Peral) el 15/01/1814, donde estarían hasta su disolución, y teniendo en cuenta el regreso de Fernando VII a España en marzo de 1814, se nombró una Comisión de Ceremonial para elaborar el específico para celebrar el aniversario del 2 de mayo siendo aprobado su dictamen el 29/03/1813 habida cuenta de que por primera vez las Cortes acudían a un acto público en Madrid. Como la Comisión preveía que a partir de ese momento serían frecuentes las salidas en público "hizo presente la necesidad de que se estableciera la etiqueta con que hubiera de verificarse" (Fernández Martín, 1992, II, p. 213). Dicho ceremonial se aprobó en sesiones secretas los días 4, 5, 14 y 18/04/1814, estableciendo además el acto de juramento de la Constitución por el rey, llegando a prever la asistencia del cuerpo diplomático al acto. Los sucesos posteriores que terminaron con el decreto de 4 de mayo de 1814 declarando nula la Constitución de 1812 y todos los hechos realizados por las Cortes de Cádiz, dejaron el tema en suspenso.

Castilla, Aragón Cataluña, Valencia y Navarra (Jovellanos, 1840: 307), y de informar en todo lo relativo a organización y ceremonial de Cortes. Estuvo formada por el conde de Ayamans que la presidía, Sebastián de Torres -vicepresidente-, Manuel Abellá, Pedro Polo de Alcocer, Antonio Capmany, Vicente Eulate, Alejandro Dolarea y José Ramírez de Cortés -Secretario con voto- (Fernández Martín, 1992, I: 494). La Junta gozó de una amplia autonomía hasta el punto de rechazar las propuestas bicamerales y pronunciarse a favor del unicameralismo, propuesta que sería la adoptada finalmente. Se trataba de evitar la separación de las clases sociales, aunque conservando el carácter estamental de ahí que se hablara de un Congreso compuesto de los tres estados (Archivo del Congreso de los Diputados, leg. 3, exp. 1).

${ }^{8}$ El 1 de octubre de 1810 se leyó en el Congreso un Reglamento provisional que no fue aprobado y se ordenó que volviese a la Cámara para modificarlo. "Dicho reglamento es provisional mientras el tiempo y la experiencia indican las faltas que pueda tener, y las mejoras de que sea susceptible" (El Conciso, 04/10/1810). Volvió a la Cámara el día 5 de octubre en que se discutió, pero no se aprobó por lo que Argüelles se acordó abordar el tema en sesiones extraordinarias de 8 a 10 de la noche nombrándose una comisión (El Conciso, 10/10/1810). Está claro que de resultas de sus modificaciones se aprobó el de 24 de noviembre. 


\section{LOS TRATAMIENTOS COMO MANIFESTACIÓN DE LA OSTENTACIÓN DEL PODER POLÍTICO Y REPRESENTACIÓN SIMBÓLICA DE LA SOBERANÍA.}

Resulta curioso que lo primero en lo que pensaron los ideólogos de todo el proceso constituyente fue en lo importante del tratamiento honorífico, y de ello se ocuparon. El tratamiento, palabra de fuertes implicaciones médicas como ocurre con protocolo, es, "titulo de cortesía que se da a una persona" (RAE). Esa vinculación médica quizás se deba a ser "la forma o los medios que se utilizan para llegar a la esencia de algo" (Wikipedia). Y es que en el tratamiento honorífico en buena medida se condensa la esencia de la persona: nos dice con una palabra la posición y/o cargo de una persona, física o jurídica, en la sociedad. Y, frente a lo que ocurre hoy en día donde tan proclives somos a prescindir y rechazar el tratamiento como forma utópica de eliminar desigualdades, en aquella época el tratamiento era muy importante, tanto que en la sesión de 05/10/1810, Capmany recriminaba a $E I$ Conciso por no incluir en sus crónicas Señor delante del apellido de los $\operatorname{diputados}^{9}$ y que motivó que se aprobase la creación de un periódico de las propias Cortes, tanto por pensar que la familiatura en el trato de los diputados iba en desprestigio de la institución, como que la información de lo acontecido en Cortes debía ser controlado por las mismas.

De hecho el 25 de septiembre de 1808 la primera medida que se adoptó para recuperar la gobernabilidad del territorio español fue la creación en Aranjuez, la Junta Central Suprema y Gubernativa de España e Indias, que adoptó el tratamiento de Majestad, por asumir el papel de jefatura de Estado provisional, motivo por el que su Sede se encontraba en Palacio - "en nombre del rey nuestro Señor", en el que se instituye ${ }^{10}$ - como "depositaria de la autoridad Soberana de nuestro amado rey Don Fernando VII"11 durante la ausencia del monarca, aunque con intensos debates sobre si la misma representaba al monarca o al pueblo, que en ausencia del monarca recuperaba así la soberanía en él depositada. "Majestad" es un "titulo Imperial, o Real, de a par de Emperador" (Covarrubias, 1611). Es decir, es un título que no puede ser utilizado a la ligera por cualquiera. De hecho y aunque entre los siglos XVI y XVII, en la lengua española se empleó para designar a la persona investida de cierta autoridad, o encargada de cumplir funciones de juez o magistrado, pronto quedó reservado para el Monarca.

El último decreto de la Junta Central antes de su disolución, de fecha 29 de enero de 1810, que proponía la convocatoria de Cortes generales y extraordinarias, señala por primera vez la división de poderes, encomendando a las futuras Cortes el poder legislativo,

\footnotetext{
9 "Al paso mostró que también á él le chocaba la falta del señor antes del apellido de los diputados en Cortes, y con la gracia que le es natural mostraban quan poco decoroso era un apellido a secas del modo siguiente: Capmany... un esportillero; Huerta... un mozo de esquina; N... otro mozo de esquina \&c." (El Conciso, 10/10/1810). La respuesta del periódico consistió en manifestar que "no es el señor el que caracteriza á una persona; pues ni Cubas con él dexará de ser un cómico, ni Capmany sin él dexa de ser un DIPUTADO EN CORTES, que el mayor carácter del español" (cursiva y mayúsculas del original).

${ }^{10}$ Real Provisión del Consejo Real de toma de cargo a los miembros de la Junta Central (Aranjuez, 25 de septiembre de 1808), en http://www.cervantesvirtual.com/portales/constitucion 1812/su obra decretos

${ }^{11}$ Comunicación de Floridablanca al Presidente del Consejo de Castilla (26 de abril de 1808).
} 
mientras el poder ejecutivo permanecía en la Regencia. Curiosamente en el Proyecto de reglamento y juramento para la Suprema Regencia, de idéntica fecha, que dejó realizado también la Junta Central, establece que la Regencia, en tanto en cuanto "despachará a nombre de nuestro amado rey Fernando VII", tendría tratamiento de Majestad, su Presidente el de Alteza serenísima y sus miembros el de "Excelencia entera"12.

Un cambio de planteamiento tendrá su proyección a nivel de tratamientos, nada más convocarse las Cortes. Las Cortes de Cádiz en la segunda sesión (25/09/1810), tomaron el título de Majestad, dejando a la Regencia el de Alteza. Se trata de un hecho sin precedentes que establece la superioridad del legislativo sobre el ejecutivo y que coloca a la Monarquía, a la que la Regencia representa, en posición inferior en la escala, con lo que por un lado con el acto se está reivindicando la soberanía popular, a la vez que se traspasan los límites de la lesa Majestad propios del Antiguo Régimen. Por su parte, el Decreto II (25/09/1810) señalaba no sólo el tratamiento que debían tener los tres poderes, sino que se establecen además las pautas para el juramento obligatorio de todas las autoridades: Cortes generales, Majestad; Poder ejecutivo: Alteza (durante la cautividad y ausencia de Fernando VII); Tribunales supremos de la nación confirmados por las Cortes: Alteza. A los efectos de este decreto son consideradas autoridades: los generales en jefes de todos los ejércitos, los capitanes generales de las provincias, arzobispos y obispos, todos los tribunales, juntas de provincia, ayuntamientos, justicias, jefes, gobernadores, y demás autoridades (civiles, militares y eclesiásticas), los cabildos eclesiásticos y los consulados. Resalta de este decreto cómo, al declararse la confesionalidad del Estado, se recoge como autoridades no sólo a las políticas y militares sino también a las altas jerarquías eclesiásticas.

Las Cortes de Cádiz pronto establecieron un Reglamento provisional del poder ejecutivo, (Decreto XXV, 16/01/1811), para regular el Consejo de Regencia, en cuyo ratificando el tratamiento de Alteza para el Consejo (cap. I, art. 5) ${ }^{13}$ y otorgando el de Excelencia para sus miembros, le confía una guardia propia, igual a la del Congreso, que debía rendirle los honores propios de Infante de España.

$Y$ es que el tratamiento a efectos institucionales suele implicar la rendición de honores y una guardia encargada de rendirlos. A este respecto, el Reglamento de 1810 había previsto que en el interior del Palacio de las Cortes, harían guardia los Guardias de Corps y Alabarderos y en exterior y galerías la guardia española y valona, "en los propios términos

\footnotetext{
${ }^{12}$ Según la Novísima Recopilación el tratamiento de Alteza Serenísima era el propio de los Infantes, aunque con el tiempo fue extendiéndose a otras personas. Desde el Real Decreto de 16 de mayo de 1788 (Novísima, 6, 12, 4) de Carlos III, la Excelencia podía ser entera o simple, siendo la primera la atribuida a Grandes, Consejeros de Estado y personas que habitualmente gozaban del título -Arzobispo de Toledo, Caballeros del Toisón, Gran Canciller y Grandes Cruces de Carlos III, Capitanes Generales del Ejército y Armada, Virreyes y Embajadores españoles o extranjeros-, y consistía en poner encima de los escritos a ellos dirigidos Excelentísimo Señor a la vez que recibían todos idénticos honores militares -salvo en la Corte- siendo la simple el resto de los supuestos y no constaba en los encabezamientos de los escritos.

${ }^{13}$ En adelante se indicarán los capítulos y artículos entre paréntesis en el caso de este Reglamento, por reiniciarse la numeración en cada uno de ellos.
} 
que unos y otros Cuerpos lo harían en el palacio del Rey" (IX, 1), encontrándose los jefes de la guardia a las órdenes del Presidente de las Cortes (IX, 2). Pero hay más: "el concepto formulado por las Cortes generales y extraordinarias de 1810 de que habían venido a sustituir en la jefatura suprema del Estado al Monarca durante su ausencia, no sólo se manifestó en las atribuciones regias de que se consideraron investidas, sino que se exteriorizó aun más, si cabe, en o referente á la guardia de las mismas" (Fernández Martín, 1992, II: 198). De ahí que los comandantes de las guardias española y valona se entendieran directamente con el Presidente "como lo hacían con la Real Persona", medida de gran alcance que dio no pocos quebraderos de cabeza, fue tema de varias sesiones secretas y públicas, e incluso conflictos con la Regencia ${ }^{14}$ que ocasionarán que el Reglamento de 1813 determine que la guardia que sirva en las Cortes será de infantería de los cuerpos que sirven en palacio, pero expresamente consta que no debe ser de alabarderos ${ }^{15}$.

El Reglamento de 1813 incorpora en cuanto a tratamiento en la correspondencia el tratamiento de Excelencia para el presidente de las Cortes y para los cuatro Secretarios de las mismas. Y por fin, el Decreto de 19 de abril de 1814 de las Cortes de Cádiz establece el título de Majestad exclusivamente para el rey a la vuelta de Fernando VII.

En cambio, y de acuerdo con la nueva mentalidad, no existe preocupación alguna por las precedencias. Tan sólo el Reglamento de 1810 establece una cierta precedencia entre los diputados que ostentan cargos en las Cortes: Presidente, Vicepresidente (que le sustituye en casos de ausencia o enfermedad), 2 Secretarios, 1 Vicesecretario (que actúa en caso de ausencia o enfermedad de cualquiera de ellos). Tampoco existe una jerarquización en el asiento de los diputados, quedando tan sólo reservado al Presidente el centro de la sala y la mesa. Pero para las votaciones se establece que comenzaban por los Secretarios, y continuaban por la derecha del Presidente, guardando los diputados el orden de asientos, votando el Presidente el último (VI, 14).

\section{LOS JURAMENTOS COMO RITUAL ALEGÓRICO SOLEMNE}

El juramento promisorio, procedente de nuestra tradición jurídica romano-canónica, pone a Dios como testigo del cumplimiento de la promesa, por lo que está férreamente vinculado con la religión ya que antiguamente se consideraba pecado el incumplimiento de lo prometido dado el aval que la divinidad suponía. Por ello este juramento va revestido de una estética y formalidad religiosa importante: se celebra en lugar sagrado, ante las

\footnotetext{
${ }^{14}$ Tras numerosos altercados con la misma, que pretendía sustituirla por una guardia de voluntarios y pese a que un Decreto XXXVI (10/04/1812) insistiendo en la necesidad de la presencia de esa guardia, poco a poco la guardia valona fue retirándose de la misión.

${ }^{15}$ Recordemos que el Cuerpo de Reales guardias Alabarderos son una guardia especial encargada en España de custodiar a los Reyes y dar realce en los actos públicos, desde su creación en 1506 por Fernando El Católico, hasta la actualidad en que conforman la unidad más antigua de la guardia Real. La guardia existente en las Cortes era la encargada de rendir honores al Rey cuando concurriese a las Cortes, hecho que nunca sucedió.
} 
Sagradas Escrituras y con la Santa Cruz presente. De ahí la reticencia de muchos de nuestros políticos actuales a "jurar" el cargo o la Constitución, acudiendo a la fórmula de la promesa.

El juramento de los miembros de la Junta Central se produjo (24/09/1810) a las 9:30 de la mañana en la Capilla del Palacio Real de Aranjuez, frente a una imagen de Cristo crucificado. En una ceremonia religiosa, juraron defender la fe católica, a Fernando VII, a sus derechos, a la constitución histórica del país, el derecho de sucesión de la familia reinante, el bien común y las costumbres de España, mantener el secreto y perseguir a los enemigos de España, en ese orden.

El Proyecto de reglamento y juramento para la Suprema Regencia (29/01/1810) establecido por la Junta Central, era similar en cuanto al contenido del juramento, si bien se incluía a continuación de la fe católica, la expulsión de los franceses y la restitución del trono a Fernando VII, y se añadía el no reconocer otro gobierno que el que en ese momento se establecía mientras las Cortes no determinasen el más conveniente, el contribuir a la formación de las mencionadas Cortes, la conservación de las leyes del país y en especial la de sucesión a la Corona y terminaba ordenando la observancia del mencionado Reglamento. Este juramento fue simple y no solemne al no realizarse en ningún recinto sagrado, y tenemos datos específicos de cómo se verificó dado que eran pocos, sólo tres, los que se encontraban en el recinto de la Isla de León y sólo tenemos constancia de que fue el presidente el que tomó juramento a los presentes según el Acta de constitución (31/01/1810).

Por lo que respecta a la regulación de las Cortes de Cádiz, ya el decreto I (24/09/10) establecía junto con la responsabilidad del ejecutivo y la rehabilitación de la Regencia, la obligación de prestar juramento a las Cortes por el Consejo de Regencia, mientras se incluía una fórmula para dicho juramento de obediencia, que ya presenta una serie de matices. La fórmula del juramento constaba de una serie de preguntas, que debían ser contestadas por los miembros del consejo de Regencia en la sala de sesiones de las Cortes, reunidas en sesión permanente, luego no se realiza en lugar sagrado. Además, varía el orden por cuanto se reconoce en primer lugar la soberanía de la Nación, representada por las Cortes, la obediencia de la normativa proveniente de la misma, la independencia, libertad e integridad de la Nación, para a continuación colocar la fe católica, la monarquía, el restablecimiento de Fernando VII, y el bien del Estado. Además, se introduce un elemento nuevo: la responsabilidad del quebrantamiento del juramento ante las leyes. Ya no estamos ante un juramento promisorio. Hasta ese momento sólo se había mencionado el castigo divino como posible sanción ante el incumplimiento del juramento, como reconocimiento de que la única instancia a la que había que dar cuenta era la divinidad y que el poder de las Cortes no conocía de la existencia de una limitación humana posible. No ocurre así con el poder de la Regencia, que se encuentra en un escalón inferior y debe dar cuenta a la nación. A las 11:00 de la noche del 24/09/1810, la Regencia acudió a la Sala de las Cortes, excepto su presidente, verificando el juramento en manos del presidente, que ocupaba un lugar 
preferente y que tenía a derecha e izquierda a los miembros de las misma (El Conciso, $26 / 09 / 1810)^{16}$. Por su parte el Decreto II (25/09/1810) establecía la obligación de que las autoridades prestasen juramento en los mismos términos y con la misma fórmula que lo había prestado el Consejo de Regencia, incluyendo además la obligación de los que se encontrasen en Cádiz y en la Isla de León jurasen directamente en la sala de sesiones de las Cortes, para que ellos y los demás jefes civiles, militares y eclesiásticos exigiesen el mismo juramento a sus subalternos, quedando habilitada la Regencia para notificar dicho cumplimiento a las Cortes.

El Acta de instalación de las Cortes generales y extraordinarias (24/09/1810) nos da datos del juramento de los diputados de las Cortes de Cádiz. Tras una rogativa de tres días y una Misa de Espíritu Santo se congregaron los diputados en el Palacio de la Regencia para salir formados una vez más a las 9:30 junto con el Consejo Supremo hacia la iglesia parroquial de San Fernando para realizar una nueva Misa votiva de Espíritu Santo, hacer una profesión de fe y realizar el juramento. A lo largo del recorrido se encontraba tendida la tropa de la Casa Real y del ejército acantonado ${ }^{17}$. Una vez dentro, el Notario mayor Nicolás María de Sierra, pronunció dos veces en voz alta la fórmula del juramento. Tras responder los diputados, fueron pasando de dos en dos a tocar los evangelios, tras lo cual el presidente concluyó el juramento conminándoles al cumplimiento. El juramento se hizo a la religión católica, conservar la integridad de la nación y liberarla de la ocupación, la conservación de Fernando VII y de la sucesión a la corona, desempeñar su cargo y guardar las leyes, salvo las que conviniese modificar. A continuación, se entona el himno Veni Sanctae Spiritu y un se celebra un Te Deum. Terminada la parte religiosa, los diputados salieron de la iglesia en formación a la sala de cortes para su instalación. Juramento promisorio en toda regla y además solemne.

El Reglamento de 1810, destinó su capítulo XI al juramento distinguiendo entre dos modelos similares en función de quien realizase el juramento: el que debían prestar los diputados, situando en primer lugar la defensa a la religión católica e inadmisión de cualquier otra, la de conservar la integridad de la nación y de Fernando VII, desempeñar fielmente su cargo guardando las leyes, y agregando guardar el secreto en los Casos en que las Cortes ordenasen mantenerlo; y el que debían prestar los miembros del Consejo de Regencia y todas las autoridades que tuvieran que jurar ante las Cortes, para el que previamente se solicitaba el reconocimiento de la soberanía nacional representada por las

\footnotetext{
${ }^{16}$ El presidente del Consejo de Regencia había dado largas a su juramento en la pretensión de introducir en el mismo las palabras "sin perjuicio de los juramentos hechos al Rey D. Fernando VII", lo que provocó airadas protestas en las Cortes contra su actitud, la velada acusación de demócratas y republicanos que implicaba, y la falta de respeto manifestada hacia las Cortes de que da cuenta de forma exhaustiva El Conciso (02/11/1810), y motivó que se votase posteriormente su sustitución.

17 “Hoy a las nueve de la mañana se reunieron los señores Diputados de Cortes en la casa consistorial, desde donde acompañados de la Regencia que presidía, se dirigieron á la Iglesia Mayor entre infinitas aclamaciones de viva la nación que hacían enternecer á todos los circunstantes, haciendo mas y mas majestuoso este acto la presencia de los brillantes batallones por entre cuyas filas pasaron los padres de la patria" (El Conciso, 26/09/1010).
} 
Cortes, y la obediencia a la normativa procedente de la misma. La diferencia entre ambos es esencial: el juramento de los diputados implicaba la sanción divina como sanción de su incumplimiento, mientras que en el del Consejo de Regencia se incluye la responsabilidad ante la nación con arreglo a las leyes. El primero es un juramento promisorio, el segundo un juramento de fidelidad.

También se regula la forma de prestar juramento de ambos: poniendo la mano sobre los evangelios, arrodillados y al frente de una cruz colocada en la mesa del presidente (XI, 3$)$, que permanecía sentado mientras los demás diputados estaban de pié $(I, 13)$. Para el juramento de los miembros del Consejo de Regencia, o recibir y despedir a los regentes si acuden a la sala de sesiones $(\mathrm{XI}, 8)$, se establece que el presidente nombre 6 diputados (si jura uno de los miembros del Consejo de Regencia) o 12 diputados, para que salgan a recibirlos a la sala de sesiones al entrar y al salir $(X I, 4)$. Cuando juran suben al solio con el Presidente para tomar asiento, ocupando siempre el Presidente el asiento central, utilizándose simbólicamente este acto como toma de posesión. (XI, 5) Si jura uno de los miembros del consejo de regencia, los demás le acompañarán para solemnizar el acto. (XI, 6).

La Constitución de 1812 supone un cambio esencial en la concepción del juramento. De un lado, el juramento de los diputados suprime toda referencia a la Monarquía, centrando el juramento en la religión, la Constitución y el cumplimiento del cargo, y se establece un juramento pautado de forma que a cada pregunta deben responder los diputados con su juramento (art. 117). De otro, se establece la obligatoriedad de que el rey preste juramento al llegar al trono de la Constitución y de las leyes del Reino (art. 173) ${ }^{18}$, de no dividir el reino, no realizar atentados contra la propiedad ni contra las libertades de los ciudadanos, castigándose el incumplimiento con la sanción divina, pero introduciendo la posibilidad del incumplimiento de lo ordenado en caso contrario, legitimando así el derecho de resistencia. Y se prevé lo mismo para la regencia (art. 196), y para el príncipe de Asturias (art. 212). Pero no se establece nada respecto de la forma de prestarlo.

\footnotetext{
${ }^{18}$ Algo que acostumbramos a olvidar es que el primer texto legal en España que establece el juramento del rey a la Constitución es el Estatuto de Bayona de 1808, que al hablar de la sucesión a la Corona (II, 5), establece la obligación del rey de prestar juramento, ante las Cortes y demás instituciones, señalando el texto y contenido del Juramento (6), que se centra en observar y hacer observar la Constitución, guardar la integridad territorial y promover el bien de la nación. Es curioso que este texto sea el punto de partida y el punto de llegada de las Cortes de Cádiz, Cortes que dieron una importancia especial al juramento tanto dentro de las mismas como, tras la aprobación de la Constitución, de las autoridades y el pueblo hacia la misma, juramento que se convierte en ritual alegórico (Reyero, 2010: 182). Hasta ese momento, desde los Reyes Católicos, y más allá del mero juramento de privilegios de la ciudad realizado por los monarcas a la entrada en las mismas, el único juramento que se pronunciaba era el de fidelidad y obediencia por parte de los súbditos, y era el único que se prestaba en las Cortes, salvo en el caso de las Cortes Aragonesas en las que existía el juramento del rey y sus oficiales de guardar los fueros y actos de Cortes (Capmany, 2007: 53). Recordemos que, "la jura real era en sus orígenes medievales la forma ceremonial de un pacto de respeto mutuo entre el rey y el reino, y a la vez un acto de reconocimiento del rey como señor natural por el pueblo" (Cárdenas, 1998: 66). Era pues un mecanismo de reforzamiento del poder. Por ello no es de extrañar que asistamos a una importante transformación del juramento en las Cortes de Cádiz, que dejó impregnado el constitucionalismo español.
} 
También se ocupa del juramento en detalle el Reglamento de 1813, que por una parte establece un cambio en la forma de realizar el juramento de los diputados: mientras un Secretario lee la fórmula, los diputados debían acercarse de dos en dos y arrodillarse en el lado derecho del Presidente, que se encontraba sentado, para poner su mano sobre los Evangelios y decir "si juro". Y por otra ratifica lo previsto en la Constitución, respecto del juramento del propio rey, el del regente o consejo de regencia, y el del príncipe de Asturias, si bien estableciendo el ceremonial con que dicho juramento debía realizarse.

Si el rey debía prestar juramento, el procedimiento consistía en que subieran al trono, situado en el hemiciclo, el presidente y los secretarios, para a continuación situarse el presidente a la derecha del rey, portando los Evangelios, y los secretarios enfrente del mismo, llevando los dos más antiguos el libro del juramento. El rey debía jurar levantándose y poniendo su mano derecha sobre los Evangelios portados por el Presidente, mientras todos los diputados permanecen de pié (149). El acto seguía con un discurso del presidente de las Cortes y otro de contestación del rey.

El juramento del regente se hacía con las mismas formalidades, variando el número de presentes en la recepción, si bien en este caso, cambiaba el escenario: las sillas se colocaban delante y fuera del trono y para jurar los secretarios más modernos en el cargo que conducen al regente o regentes delante de la mesa del presidente, leen el decreto de nombramiento para pasar los regentes al lado derecho del presidente y arrodillados juran leyendo la fórmula el secretario, mientras los diputados permanecen sentados hasta su salida, momento en que se levantan. También aquí se pronuncia un discurso por el presidente que es contestado por el regente.

El juramento del príncipe de Asturias, estaba previsto para las primeras cortes convocadas tras el cumplimiento de los catorce años por el mismo. Las formalidades son las del juramento del regente, variando igualmente el número de diputados de la recepción, si bien en ese caso se sitúa una silla fuera del trono, bajo un dosel salvo que asista el propio rey, en cuyo caso el ceremonial se ajusta a lo dispuesto para la presencia de su majestad en las Cortes no se pone dosel a su asiento y se coloca un escalón más abajo que el del rey y a su derecha. El presidente dirige un discurso que el príncipe no contesta.

El juramento pues está cargado de simbolismo y solemnidad distinguiendo claramente las diferentes posiciones protocolarias existentes en el nuevo orden constitucional establecido.

\section{SEMIÓTICA Y CORTES DE CÁDIZ: LAS CEREMONIAS COMO ESCENIFICACIÓN DEL PODER ESTABLECIDO}

"Las ceremonias oficiales se enmarcan en el universo de las manifestaciones externas del poder: recogen la estructura de poderes e instituciones, unipersonales o colegiados: señalan el lugar que corresponde a autoridades e instituciones, a otros colectivos con carácter representativo y a personalidades destacadas; son un capital de legitimidad para las 
instancias que en ellas participan; usan y aplican símbolos de la herencia histórica y cultural colectiva; y hacen presente una auto-imagen de la sociedad como comunidad" (Marín Calahorro, 1997 p. 19). Todo esto se refleja perfectamente en las ceremonias realizadas en torno a las Cortes de Cádiz.

La ceremonia de instalación de la Junta Central se hizo a la antigua usanza, en la Capilla del Palacio Real de Aranjuez, en dos ceremonias una religiosa y otra civil. Los diputados se reunieron en la Sacristía para salir formados a colocarse en los bancos de la Capilla a uno y otro lado. Se celebró una Misa oficiada por el arzobispo de Laodicea, que fue el primero en jurar sobre los santos evangelios por reunir la condición de diputado, continuando con el de los demás miembros. TeDeum cantado, con el que concluye la ceremonia religiosa. Estando formado un batallón de tropas ligeras de Valencia en dos filas desde la salida de la Capilla hasta la Escalera del Palacio Real, los diputados pasaron por delante para instalarse en una de las Salas de Palacio para las reuniones. A continuación, los diputados salen a la gran galería de la fachada principal de Palacio, con su presidente interino Floridablanca al frente, para saludar a la gente congregada -igual que realizaban los monarcas- y proclamar a Fernando VII en medio de aclamaciones y vivas. Paso a la sala donde se colocan y tras un breve discurso de su presidente se declara a la Junta legítimamente constituida. La simbología que se transmite es de clara toma del poder de forma provisional en nombre del monarca.

La ceremonia de apertura de las Cortes de Cádiz reúne de nuevo una parte religiosa y una civil. Desde la Sala Capitular de las Casas Consistoriales se trasladaron los diputados a la Iglesia Mayor parroquial de San Fernando (Iglesia de San Pedro y San Pablo), donde el cardenal arzobispo de Toledo, D. Luis María de Borbón y Vallábriga, celebró Misa de Espíritu Santo, tras la que se prestó el cuádruple juramento. Tras el mismo los diputados se trasladaron al Teatro Cómico (Teatro de las Cortes) ${ }^{19}$, acondicionado al respecto para la ocasión. Allí, tras un breve discurso del presidente del Consejo de Regencia -simulando los discursos de apertura de las Cortes realizados por el Rey y vinculando las Cortes a la tradición castellana-, las Cortes quedan establecidas y una vez que la Regencia abandona el local -como era habitual que hiciese el rey que no asistía a las deliberaciones-, los diputados eligen presidente (Ramón Lázaro de Dou y Bassols) y secretario (Evaristo Pérez de Castro y Brito). Este último lee la memoria que había dejado el Consejo de Regencia, manifestando las Cortes haberse dado por enteradas. A media tarde se decide que acudan los miembros del Consejo de Regencia para prestar su juramento a las Cortes, estableciéndose el Ceremonial para dicho juramento, aunque dicho juramento sólo se verifica por cuatro de los miembros del Consejo, su presidente se había excusado alegando motivos de salud, en un

\footnotetext{
19 “Cádiz, 24 de septiembre. Hoy por la mañana en la Real Isla de león se ha dado principio a la celebración de las Cortes extraordinarias de todos los reinos y dominios de España. La salva general de los buques de guerra de la bahía y de los baluartes de la plaza ha solemnizado este plausible acontecimiento, que promete las más felices consecuencias para la victoria de la causa de la nación y sólido establecimiento de su independencia y prosperidad" (Gaceta de la Regencia de España e Indias, 25/09/1810).
} 
desafío a las Cortes (García León, 2009, p. 164). La sesión del primer día duró quince horas continuas (desde las nueve de la mañana a las doce de la noche) ${ }^{20}$.

El Reglamento de 1810, no recoge ceremonial alguno dando tan sólo unas breves notas sobre la recepción del Consejo de Regencia por las Cortes. La presencia del Consejo en la sala de sesiones suponía ser recibidos por el presidente, que permanecía sentado (este hecho simboliza la mayor autoridad del mismo) hasta que lleguen a las gradas, momento en que se levanta, suben los regentes y el presidente les asienta, "ocupando este la preferencia" (XI, 7). Asistiendo algún regente a las sesiones, los diputados debían permanecer levantados hasta que se sentasen los regentes y levantarse cuando se iban (XI, 9). Pero no se podía deliberar nada en presencia de los mismos, por lo que si acudían era para decir algo, en cuyo caso conducía el acto el presidente (XI, 10), como anfitrión del acto. La presencia de príncipes extranjeros se deja a la posterior regulación de las Cortes.

El traslado de las Cortes desde la Isla de León hasta la ciudad de Cádiz, se realizó "sin ceremonial ni aparato alguno" (Decreto XXXVI, 18/02/1811).

La Constitución de Cádiz no prevé específicamente nada respecto al ceremonial en sí, tan sólo se pronuncian levemente respecto de la apertura y cierre de las Cortes, a las que debía asistir el rey (art. 212), que debía entrar en la sala sin guardia, y hacer un discurso de propuesta que es respondido por el presidente de las Cortes (art. 123). Expresamente manifiesta que el ceremonial de recibimiento y despedida del rey se deja para su regulación en el Reglamento de Gobierno Interior.

En cambio, el Reglamento de 1813 ya se ocupa de dar una mayor presencia de las Cortes en la vida pública. Por un lado, se establece que las tareas de acompañamiento dentro del recinto de las Cortes corresponden a los dos secretarios más modernos cuyas funciones son de acompañamiento (art. 46) -al rey al Trono; al príncipe de Asturias, a la regencia a sus asientos; a los diputados a la jura y a quien debía presentarse a las Cortes- y dirigir los actos solemnes de juramento. Por otro lado, se determina la forma de visualizar la presencia de las Cortes fuera del recinto de las mismas acudiendo a Palacio. Para ello se establecía una pequeña diputación de dos diputados que se desplazaba a Palacio en las siguientes ocasiones: durante la enfermedad del rey, acudiendo a la antecámara para saber del estado de salud del rey; cuando éste fallecía para firmar el testimonio de defunción; en los actos de presentación de príncipes e infantes recién nacidos en Palacio; al bautizo, firmando la partida que refrendaba el Secretario de Gracia y Justicia, una copia de las cuales se custodiaba en las Cortes; y cuando se presentaba al rey el decreto reconociendo sucesor y príncipe de Asturias del hijo del Rey (en cuyo caso la diputación era de 24 diputados).

\footnotetext{
20 "Sin alimento ni descanso, y haciendo en la primera sesión lo que sería trabajo de algunos meses para una asamblea ya organizada" (El Conciso, 26/09/1810).
} 
Cuando la diputación acudía a Palacio desde su entrada hasta su salida se le rendían "honores de Infante" (art. 132), y al presentarse debía hacer acatamiento al monarca, actuando el más antiguo como portavoz.

De la misma manera se regulan las recepciones en el recinto de las Cortes previstas que eran:

1. Recibimiento del rey. El rey entraba descubierto (algo inaudito), mientras que los diputados se levantaban y permanecían así hasta su asiento, permaneciendo los jefes de Palacio en pie a la espalda del trono (obsérvese la estética), y situándose el resto de la comitiva en la barandilla. A la derecha del trono se colocaba una silla para el presidente de las Cortes, colocándose los cuatro secretarios en primer orden de asientos cerca del presidente con una mesa delante (arts. 147 y 148). A su salida se levantaban los diputados.

2. Recibimiento del regente, en cuyo caso la silla se colocaba delante y fuera del trono con un almohadón al pie, aunque si el motivo de la visita era el juramento, la diputación se reducía a 12 diputados y sólo salen a recibirle a la primera puerta del salón. Los diputados sólo permanecían de pié hasta que se llegaba a la mitad del salón momento en que se sentaban. A la derecha se colocaba la silla para el presidente. A la salida una diputación de 12 les acompañaban hasta el lugar señalado y 4 hasta el Palacio de Gobierno.

3. Recibimiento del príncipe de Asturias, en cuyo caso la silla estaba fuera del trono y bajo dosel, entrando el príncipe acompañado de los jefes principales de su servidumbre que se situaba detrás y el resto del acompañamiento en la barandilla.

Para todas estas ceremonias una diputación variable en número (30 para recepción del rey, 20 para el regente o consejo de regencia, 24 para el príncipe de Asturias, con lo que se inicia una gradación en los honores) salía al exterior del edificio o a pie del coche y le acompañaba hasta el trono o la silla habilitada al respecto.

El Reglamento establece que serán las Cortes las encargadas de hacer un decreto con las ceremonias con que se debe hacer la proclamación del rey (art. 141).

\section{LOS ESCENARIOS: EL ELEMENTO ESPACIAL MATERIAL}

Siguiendo a Otero Alvarado, el ceremonial es identificable por tres elementos constitutivos: los espacio-temporales, los personales y los normativos (Otero, 2004, pp. 280281). Los escenarios conforman el apartado material del elemento espacio-temporal. Vamos a ocuparnos someramente de ellos.

Las ciudades de San Fernando y Cádiz, fueron las que proporcionaron los edificios a las ceremonias directamente relacionadas con las Cortes de Cádiz, aunque con el precedente 
del palacio de Aranjuez, donde se realizó la ceremonia de instalación de la Junta Central. La escenificación en este último caso estuvo perfectamente planeada pues el mensaje consistía en reivindicar la potestad de la Junta Central, y escenificar el traspaso de la soberanía en sus provisionales depositarios.

\subsection{Isla de León (San Fernando)}

Varios fueron los edificios relacionados con las ceremonias en esta localidad.

- El Convento de la Enseñanza de María (Colegio de la Compañía de María) de San Fernando, donde se instaló el Consejo de Regencia (31/01/1810), tras haber sido desalojado por orden del día 16 anterior, y donde presumiblemente se realizó la constitución del mismo, al ser sólo tres los miembros de dicho Consejo presentes.

- Casa Consistorial de San Fernando, donde el 24 de septiembre de 1810 se congregaron los diputados para salir a la Iglesia Mayor a prestar juramento, y en cuya Sala Capitular acordaron la fórmula del juramento. Desde ahí desfilaron hasta la Iglesia Parroquial para prestarlo.

- Iglesia Mayor de San Pedro y San Pablo (Iglesia Parroquial), donde el 24 de septiembre de 1810 prestaron su juramento.

- Teatro Cómico de la Isla (Real Teatro de las Cortes), donde se celebraron las primeras reuniones, hasta el 20 de febrero de 1811 . Fue reformado por el ingeniero naval Antonio Prat para adecuarlo a la finalidad, modificando el escenario y el patio de butacas, para igualarlos. Lo convirtió en un hemiciclo de forma elíptica presidido por un retrato del rey Fernando VII21 y en el centro una mesa -que se conserva en el Ayuntamiento- destinada al presidente y secretarios. Los diputados se sentaron en dos hileras de asientos al pie de los palcos, en el espacio igualado, mientras éstos se destinaron al cuerpo diplomático y autoridades; los pisos altos se destinaron para el público en general. A cinco metros de la puerta existía una elevación con una barandilla que se utilizó como espacio para dirigirse a las Cortes. Se colocó un cuadro de Fernando VII de tamaño natural de Juan Cerruti, a modo de presidente, bajo un dosel en un tablado con tres escalones y una silla que permanecía vacía, situada sobre una alfombra. En el centro del salón había una mesa con cinco sillones para el presidente y los secretarios, y dos tribunas a la derecha y la izquierda a la que se subía por dos escalones. El único adorno existente era una medalla alegórica de tres metros de diámetro con un león sujetando los dos mundos, representando las fuerzas de España (Quintana Martínez, 1910, p. 52-53). Sobre este escenario El Conciso admitió, tras haberlo criticado, que "a falta de un edificio hecho expresamente para

\footnotetext{
21 "Sentado el Consejo de Regencia baxo el solio donde estaba colocado el retrato del séptimo de los Fernandos, pronunció el Presidente un discurso en el que entre otras cosas recordó la triste situación en que se hallaba la España quando tomó el mando la Regencia" (El Conciso 26/07/1808).
} 
cortes, ninguno es más comodado que el teatro". Y es que la mejor manera que tienen las personas de comunicar es si se encuentran cara a cara, por lo que la mejor distribución de los grupos comunicativos es la realizada en forma de " $U$ ".

\subsection{Cádiz}

En la ciudad de Cádiz, el escenario queda reducido a un edificio: La Iglesia Oratorio de San Felipe Neri, donde se instalaron las Cortes tras su traslado. De nuevo un edificio con planta elíptica de grandes cualidades acústicas y gran capacidad, que una vez más rehabilitó Antonio Prat ${ }^{22}$, cuya elección no estuvo ausente de polémica por ser un edificio religioso (García León, 2012, pp. 129).

Tan sólo el Reglamento de 1813 se ocupa del lugar de desarrollo de las sesiones de las Cortes. En él se busca el auditorio más adecuado: un salón con disposición circular para que a derecha e izquierda se coloquen los diputados facilitándose la audición. Este espacio estaba cuidadosamente estudiado. En la cabecera había que colocar un trono con su dosel, colocado de forma que pudieran situarse a la espalda del rey los jefes de Palacio (4), y una silla vuelta. Cerca del trono, en medio del salón una mesa con la silla del presidente. A los dos lados del mismo las sillas de los cuatro secretarios, que se quitan cuando el rey asiste a las Cortes. El entorno espacial se completa con una mesa sobre la que se sitúa un crucifijo, dos ejemplares de la constitución, dos del reglamento, los códigos legales, la lista de los diputados y de las comisiones existentes (10). Se habilita una galería a la derecha del Trono para los embajadores, los príncipes extranjeros, secretarios del despacho, consejeros de estado y magistrados, el jefe político de la capital y los generales nacionales y extranjeros (8). Se señala un sitio de honor, pero en un lateral a las altas jerarquía del Estado e invitados extranjeros. Por último, se ultima un lugar especial para los taquígrafos.

\subsection{Teatro de los Caños del Peral}

Construido como corral de comedias en un antiguo lavadero público en la Fuente de los Caños del Peral, en 1708, el teatro vinculado económicamente a la Casa Real, suspendió sus actividades durante la guerra de la Independencia, para ser derruido en 1816 a raíz de la reforma de la Plaza de Oriente y posterior construcción del Teatro Real.

\section{LOS PÚBLICOS COMO ELEMENTO PERSONAL: COMPORTAMIENTO Y DRESS CODE}

Un aspecto novedoso de las Cortes de Cádiz, fue la asistencia libre de público a los debates, lo que permitió, asimismo, la presencia de la prensa en las sesiones y su contribución a crear un determinado estado de opinión. Las sesiones dejaban de ser secretas para convertirse en públicas (Durán López, 2007). La comunicación adquiere así un carácter

\footnotetext{
22 “La disposición, la nobleza y elegancia del salón hacen el elogio del Sr. Prat, autor y director de esta obra y llamaron la atención de los espectadores que desconocían la antiguo iglesia, la cual quedando intacta, ha sido tan bellamente transformada" (El Conciso, 25/02/1811)
} 
esencial en todo el proceso. La puesta en escena de las ceremonias fue debidamente calculada, y de la misma manera el día a día de los debates. El pueblo está doblemente informado: por su propia asistencia a las sesiones y por los "artículos de Cortes" de los periódicos, máxime porque el Diario de Sesiones no se comenzó a publicar hasta tres meses después de iniciadas las reuniones, salía con mucho retraso y las deliberaciones eran extractados y adaptados a la versión oficial, en muchas ocasiones cuestionada por no ser imparcial.

Aunque hombres y mujeres asistieron a las primeras sesiones (El Observador, 25/09/1808) en el Reglamento de 1810 se prohibió a las mujeres la entrada en ninguna de las galerías de la sala de sesiones, prohibición ratificada por el Reglamento de 1813, pudiendo tomar asiento los hombres de cualquier categoría y condición en cualquiera de los sitios habilitados menos la primera división de la galería baja a la derecha del dosel que quedaba reservada para el cuerpo diplomático extranjero y los generales en jefe de los ejércitos españoles y extranjeros asistentes.

También se establece, en el Reglamento de 1810, cómo debe comportarse el público en la recepción del juramento a diputados: todos los asistentes debían ponerse de pie excepto el presidente $(1,13)$. En cambio, nada quedó establecido acerca del comportamiento general del público durante las sesiones y si bien su actitud fue pacífica en las sesiones celebradas en la Isla de León, no ocurrió así al trasladarse a Cádiz en el que eran frecuentes las intervenciones ruidosas hasta el punto de obligar, por ejemplo, a levantar la sesión pública del 26 de octubre de 1811 debido a incidentes desagradables ${ }^{23}$ (Fernández Martín, 1992, II, pp. 175-197).

No se reglamentó para nada la vestimenta, con que el público debía asistir pero sí se estableció un código de vestimenta -dress code- específico para los diputados en determinados actos: los diputados que por su estado o clase no tuviesen uniforme debían vestir con traje negro cuando el rey, el príncipe o los regentes asistiesen a las Cortes o tuviesen que acudir a las Cortes (Reglamento de 1813, art. 11). Aun así la vestimenta fue utilizada como argumento para prohibir la entrada a algún periodista a la Sala, con las consiguientes protestas de su periódico.

\section{CONCLUSIONES}

El ceremonial parlamentario es el primero de los elementos del Protocolo de Estado en evolucionar de acuerdo con los nuevos principios políticos, separándose del protocolo de Corte.

\footnotetext{
${ }^{23}$ Se ordenase por las Cortes que se modificase el Reglamento interior para regular el tema y garantizar la seguridad de los diputados. Los altercados en el hemiciclo eran cada vez más frecuentes, llegando a ser importantes cuando se expulsó al Nuncio de S.S. Pedro Gravina por su conducta la abolirse el tribunal de la Inquisición en julio de 1813, y cada vez eran más frecuentes las agresiones a los diputados y los insultos, siendo objeto de distintas sesiones pero sin tomarse medidas contundentes.
} 
La distribución de los tratamientos de las autoridades se hará por importancia jerárquica en relación con la soberanía nacional, de acuerdo con el nuevo orden instaurado.

La adopción de una determinada vestimenta iniciará un código de vestimenta concreto adecuado a los tiempos en el que no obstante se permiten los uniformes en cuanto distintivos honoríficos.

El valor simbólico de la Presidencia y las preeminencias y prerrogativas concedidas, inciden en la posición central como la predominante, en una colocación visual concreta es los escenarios utilizados. La igualdad entre diputados se manifiesta en la no asignación de los escaños, aun así, para ciertas autoridades y personalidades se les reservará un determinado espacio destacado a propósito.

Existe una fuerte presencia del elemento religioso en todo el ceremonial parlamentario, fruto de la confusión Iglesia-Estado, que incidirá especialmente en el juramento de diputados y regentes que será seguido posteriormente en todas las tomas de posesiones de cargos públicos en nuestro país con una ordenación espacial que sitúa en una mesa un crucifijo, los evangelios, sobre los que se deposita una mano, y el texto Constitucional.

\section{BIBLIOGRAFÍA}

CAPMANY Y DE MOTPALAU, A. de (2007), Práctica y estilo de celebrar cortes en el Reino de Aragón, Principado de Cataluña y Reino de Valencia y una noticia de los de Castilla y Navarra, estudi introductori E. Serra y J. Fontana, Base, Barcelona.

CÁRDENAS GUTIÉRREZ, S. (1998), "De las juras reales al juramento constitucional: tradición e innovación en el ceremonial novohispano, 1812-1820", en La supervivencia del Derecho español en Hispanoamérica durante la época independiente, UNAM, México, 63-93.

COVARRUBIAS DE OROZCO, S. de (1611), Tesoro de la lengua castellana o española, Luis Sánchez, Madrid.

ESCUDERO, J. A. (dir.) (2011), Cortes y Constitución de Cádiz. 200 años, 3 vols., Madrid, Espasa.

FERNÁNDEZ MARTÍN, M. (1992), Derecho parlamentario español, 3 vols., Congreso, Madrid.

GARCÍA LEÓN, J. M. (2012), En torno a las Cortes de Cádiz: (anécdotas, curiosidades, hechos y gentes de aquella magna asamblea), Quorum editores, Cádiz.

--- (2009), Las Cortes en la Isla de León, Cádiz, Quorum Editores.JOVELLANOS, G. M. de (1840), Memorias, en LINARES Y PACHECO, Venceslao de, Obras del Excelentísimo Señor D. Gaspar Melchor de Jovellanos, VII, Imprenta de Francisco Oliva, Barcelona. 
MARÍN CALAHORRO, F. (1997), Fundamentos del protocolo en la comunicación institucional, Síntesis, Madrid.

OTERO ALVARADO, M. T. (2011), Protocolo y empresa. El ceremonial corporativo, UOC, BARCELONA.

--- (2009), Protocolo y organización de eventos, UOC, Barcelona.

--- (2005), "Los acontecimientos especiales como acciones de relaciones públicas: el ceremonial y el protocolo", en CASTILLO ESPARCIA, A. (coord..), Comunicación organizacional: teorías y estudios, Málaga, 123-163.

--- (2004), "Relaciones Públicas, Ceremonial y Protocolo", en ARCEO VACAS, J.L. Las relaciones públicas en España, McGraw Hill Interamericana de España, 277-288.

Reglamento para el Gobierno Interior de las Cortes (1810) Imprenta Real, Cádiz.

SÁNCHEZ GONZÁLEZ, M. D. M. (2011), Fundamentos del ceremonial y del protocolo, Síntesis, Madrid.

------ (2012) , Protocolo. Tradiciones, Actualidad y Crisis, Sanz y Torres, Madrid.

SUAREZ, Federico (1982), Las Cortes de Cádiz, Universidad de Navarra, Navarra.

\section{WEBGRAFÍA}

Colección de los Decretos y Órdenes que han expedido las Cortes Generales y Extraordinarias (1811-1813), 3 vols. Cádiz, Imprenta Real, http://bib.cervantesvirtual.com/servlet/FichaTituloSerieDeObra?id=269\&portal=56

DURÁN LÓPEZ, Fernando, "Prensa y parlamentarismo en Cádiz en el primer año de las Cortes: El Conciso (septiembre de 1810- agosto de 1811), El Argonauta Español, 4 (2007), http://www.argonauta.imageson.org/document97.html

La constitución española de 1812, documentos y estudios de acceso directo en http://www.cervantesvirtual.com/portales/constitucion 1812

Documentos históricos incluidos en el texto o referencias a ellos, biblioteca virtual Miguel de Cervantes, http://www.cervantesvirtual.com 